microscopy for second year students in chemistry and biology at the Massachusetts Institute of Technology. The object of the course is to give facility in the manipulation of the microscope and an acquaintance with the scope of its practical application.

The first four chapters consider the microscope and its accessories, and the other eight chapters deal with the starches, adulterations of food and drugs, textile fibers, paper, medicine and sanitation, forensic microscopy, microchemistry, petrology and metallurgy.

Each subject is dealt with in a general manner to give the student the principles and the point of view. Exercises are then given to illustrate the methods necessary for the elucidation of the questions which arise in actual practise.

The book is well conceived and satisfactorily worked out. The statements are usually clear and concise. As planned by the author, it is an introduction to the subject, and was designed for use by a teacher possessing knowledge of the more elaborate books, and the monographs bearing upon the various subjects. For the student, excellent references to good sources for further information are given with each chapter so that those especially interested can follow out the subject.

It is not particularly adapted for private learners, as the directions are frequently too brief without the supplementary instruction which naturally goes with a laboratory course. Two directions would prove unsatisfactory in practise: On page 41 the student is told to transfer cover-glasses from the potassium dichromate, sulfuric acid cleaning mixture to fifty per cent. alcohol. After a thorough rinsing in clean water, should have been added. On page 28 under the directions for using the Abbe condenser, it is said: 'In general an opening [of the diaphragm] about the size of the front lens of the objective will yield good results.' While this applies to lighting, when no condenser is used it would lead one to light with a less aperture when using an oil immersion objective than when using a low power dry objective. It contravenes the principles given in the preceding chapter. These and a few other slips will be easily remedied by the teacher and will be naturally righted in a new edition.

It is a source for congratulation that books of this kind are originating from the laboratories of our country, and it is hoped that the number will increase.

S. H. G.

The Structure and Development of Mosses and Ferns (Archegoniates). By Douglas Houghton Campbell, Ph.D., Professor of Botany in the Leland Stanford Junior Lniversity. New York, The Macmillan Company; London, Macmillan \& Co., Ltd. 1905. All rights reserved. Pp. vii +657 . 8vo. It is but a little more than ten years since the first edition of this book appeared, and now we have a second and considerably revised edition, in which much new matter has been added. By an odd oversight, the fact that this is a second edition is not indicated on the title page, although it is clearly stated in the 'Preface to the Second Edition' with which the volume opens. In this revision, the whole book has been printed from new type, none of the old stereotype plates having been used. This has given the author as much freedom in the preparation of the present book as though it were wholly new, and he has not been obliged to confine his changes to such as could be made to conform to the limitations of the old plates. The result is that this is a new book, and while it resembles the earlier one, and contains much matter which was in that edition, there is scarcely a page or paragraph in which the author has not made some changes of greater or less importance.

The new book follows the same general sequence as the old one, and, on a cursory glance, the reader sees little difference, yet a closer examination shows many changes and additions. The more important changes are those in the treatment of Marattiales, Isoetaceae and Lycopodinae. In the old edition, the Isoetaceae were discussed in connection with the Marattiales, to which they were regarded as related, but in the new book we find them taken up after the Lycopodinae, being regarded as 'sufficiently distinct to warrant the establishment of a separate order, Isoetales.' 
Two wholly new chapters have been added, viz., the 'Nature of the Alternation of Generations,' and 'Fossil Archegoniates.' The whole number of pages in the earlier book is 544, while in the present volume it is 657 . So, too, there are 266 figures in the old book, and 322 in the new. The amount of enlargement of the bibliography may be estimated from the fact that it covers 13 pages in the first edition, and more than 23 in the second.

In his closing chapter, the author presents a revision of the summary and conclusions of his earlier book. Briefly, he now holds that the archegoniate series began in the green Algae near Coleochaete; that the Liverworts are the most primitive of existing archegoniates, and that other groups have descended from them. The peculiar chromatophore of Anthocerotaceae possibly suggests the independent origin of this group, and this with other structural facts requires that they be accorded higher rank than heretofore, possibly that of a class coordinate with 'Liverworts on the one hand and the Mosses on the other.' Pteridophytes still consist of three classes, all evidently related to the Anthocerotes, but representing entirely different lines of development. The eusporangiate ferns are regarded as the lowest of the Filicinae; Hymenophyllaceae, while of pretty ancient origin, are regarded as an aberrant group; and the Polypodiaceae constitute the modern fern type. "That heterospory arose in a number of widely remote groups is unquestionable." This suggests the possibility of a multiple origin of the spermatophytes. "Except for their siphonogamic fertilization, Gymnosperms are much nearer the Pteridophytes than they are to the Angiosperms." "The close resemblance between the Conifers and the Lycopods, especially Selaginella, probably points to a real relationship." Cycads are regarded as descended from fern-like ancestors. While the position of Isoetales is still in doubt, it is regarded as possible that the Angiosperms may have arisen from them.

This edition without question must prove to be as helpful and suggestive as the one it supplants, and will be used by all students who wish to obtain a clear notion of the structure and relationship of higher plants.

\section{The University of Nebraska.}

Charles E. Bessey.

\section{SCIENTIFIC JOURNALS AND ARTICLES.}

The first article in the September number of the American Geologist- 'Pleistocene Features in the Syracuse [N. Y.] Region,' by Professor H. L. Fairchild-was prepared for the field program of the meeting of Section $\mathrm{E}$ of the American Association for the Advancement of Science at Syracuse last summer and is illustrated by two plates. Professor Charles S. Prosser contributes a paper entitled 'Notes on the Permian Formations of Kansas.' The recent investigations concerning the age of the upper Paleozoic formations of Kansas are reviewed and it is shown that the European and American geologists who have studied the subject most carefully in recent years correlate them with the Permian. 'The Atlantic Highlands Section of the New Jersey Cretacic' is described by Mr. J. K. Prather and is illustrated by three plates. Professor William H. Hobbs publishes 'Contributions from the Mineralogical Laboratory of the University of Wisconsin.' It consists of a description of minerals from various localities, illustrated by one plate of metallic copper from Soudan, Minn., and figures of other minerals.

The leading article in the SeptemberOctober number of the Journal of Geology is by Professor Rollin D. Salisbury on 'The Mineral Matter of the Sea, with some Speculations as to the Changes which have been involved in its Production.' Dr. Reginald A. Daly contributes a paper on "The Classification of Igneous Intrusive Bodies,' which is illustrated by nine figures. Mr. J. K. Prather describes 'Glauconite' from the (Cretaceous) Greensands of New Jersey and gives a plate of photomicrographs. "The Mesozoic of Southwestern Oregon' is described by Mr. George D. Louderback. The rocks are called the Myrtle group or series and the Dillard series. Their lithologic characters, economic relations and areal distribution are well de- 